\title{
Papers
}

\section{Monitoring compliance with the International Code of Marketing of Breastmilk Substitutes in west Africa: multisite cross sectional survey in Togo and Burkina Faso}

\author{
Victor M Aguayo, Jay S Ross, Souleyman Kanon, Andre N Ouedraogo
}

\begin{abstract}
Objectives To monitor compliance with the International Code of Marketing of Breastmilk Substitutes in health systems, sales outlets, distribution points, and the news media in Togo and Burkina Faso, west Africa.

Design Multisite cross sectional survey.

Participants Staff at 43 health facilities and 66 sales outlets and distribution points, 186 health providers, and 105 mothers of infants aged $\leqslant 5$ months in 16 cities.

Results Six (14\%) health facilities had received donations of breast milk substitutes. All donations were being given to mothers free of charge. Health providers in five (12\%) health facilities had received free samples of breast milk substitutes for purposes other than professional research or evaluation. Health professionals in five $(12 \%)$ health facilities had received promotional gifts from manufacturers. Promotional materials of commercial breast milk substitutes were found in seven $(16 \%)$ health facilities. Special displays to market commercial breast milk substitutes were found in $29(44 \%)$ sales and distribution points. Forty commercial breast milk substitutes violated the labelling standards of the code: 21 were manufactured by Danone, 11 by Nestlé, and eight by other national and international manufacturers. Most $(148,90 \%)$ health providers had never heard of the code, and 66 mothers $(63 \%)$ had never received any counselling on breast feeding by their health providers.

Conclusion In west Africa manufacturers are violating the code of marketing of breast milk substitutes. Comparable levels of code violations are observed with (Burkina Faso) or without (Togo) regulating legislation. Legislation must be accompanied by effective information, training, and monitoring systems to ensure that healthcare providers and manufacturers comply with evidence based practice and the code.
\end{abstract}

\section{Introduction}

United Nations' agencies, governmental and nongovernmental institutions, professionals, and scientists have for many years emphasised the importance of breast feeding for the optimal growth and development of children. In 1981, the World Health Assembly adopted the International Code of Marketing of Breastmilk Substitutes as a minimum international standard to ensure the proper use of breast milk substitutes. The code is based on adequate information and appropriate marketing and distribution practices (article 1). ${ }^{1}$ The assembly has since adopted several resolutions that are relevant to the code and enjoy the same status. By 1996, all member states had affirmed their support to the adoption of national legislation or other suitable measures to give effect to the principles of the code. In west Africa, few countries have adopted national policies to implement these principles. This is of concern as recent findings suggest that bottle feeding is being encouraged by the increased value placed on "modern" behaviours and through contact with western health practices, exposure to mass media, and aggressive marketing of breast milk substitutes. ${ }^{2}$ It is therefore crucial to monitor the marketing practices of manufacturers and to ensure that their conduct conforms to the code and relevant resolutions.

We monitored compliance with the code in Togo, a country without legislation in accordance with the code, and Burkina Faso, which has legislation regulating the marketing of breast milk substitutes. We monitored compliance with the code in health facilities (hospitals, maternity units, mother and child clinics, community health centres), distribution points (pharmacies and markets), and the news media, identified common violations (if any) of the code, and formulated policy recommendations.

\section{Methods \\ Survey sites and participants}

To be included in the study sites had to be easily accessible by road, have at least one health facility and three distribution points (pharmacies, and markets or supermarkets) or be close to the border with a neighbouring country as this could increase the risk of marketing practices that do not comply with the code because of legislation differences and illegal trade and exchanges. In Lomé, Ouagadougou, and Bobo-Dioulasso we monitored compliance with the code in a random sample of health facilities and distribution points. In the other sites we monitored compliance in all health

\section{Editorial by \\ Waterston \\ Helen Keller International, Regional Office for Africa, New York, NY 10010, USA \\ Victor M Aguayo regional nutrition and child survival adviser for Africa \\ Academy for Educational Development, Washington, DC 20009, USA \\ Jay S Ross policy coordinator, LINKAGES project \\ International Baby Food Action \\ Network, Regional Office for West \\ Africa, 01 BP 1776 \\ Ouagadougou, \\ Burkina Faso \\ Souleyman Kanon senior programme officer \\ World Health Organization, Regional Office for Africa, BE-773 \\ Harare, Zimbabwe \\ Andre N \\ Ouedraogo \\ regional nutrition adviser \\ Correspondence to: V M Aguayo \\ vaguayo@ \\ hkimali.org}

bmj.com 2003;326:127 
Table 1 Total population of sites included in survey in Togo and Burkina Faso

\begin{tabular}{lc}
\hline Togo & Population \\
\hline Lomé & 764439 \\
\hline Aneho & 231645 \\
\hline Kpeme & 90255 \\
\hline Tsevien & 243476 \\
\hline Afagnan & 36481 \\
\hline Vogan & 228789 \\
\hline Total & 1595085 \\
\hline Burkina Faso & 1096513 \\
\hline Ouagadougou & 839240 \\
\hline Bobo-Dioulasso & 296096 \\
\hline Banfora & 355944 \\
\hline Tenkodogo & 76500 \\
\hline Cinkanse & 40000 \\
\hline Pouytenga & 470000 \\
\hline Ouahigouya & 322121 \\
\hline Fada & 142064 \\
\hline Po & 364493 \\
\hline Koudougou & 4002971 \\
\hline Total &
\end{tabular}

facilities and distribution points. Researchers carried out interviews with mothers and health providers (doctors, nurse, midwives) in the health facilities included in the survey. In Togo, five mothers with an infant aged $\leqslant 5$ months were randomly selected and interviewed in every facility. In Burkina Faso, five mothers with an infant aged $\leqslant 5$ months were randomly selected and interviewed in every second facility. If fewer than five eligible mothers were attending the health facility at the time of the survey, all of them were interviewed. Researchers interviewed all health providers involved with the care of mothers and young infants in the same facilities where mothers were interviewed.

\section{Survey tools}

We used five data collection tools (structured questionnaires and checklists) built on previous experience by The Network ${ }^{3}$ to assess compliance with the code in health facilities, distribution points, and the news media; health providers' knowledge about the code; and health providers' breastfeeding counselling and manufacturers' marketing practices aimed at mothers. Researchers interviewed staff at different levels of technical and administrative responsibility. All interviews were confidential.

Data collection

Two survey teams collected data in NovemberDecember 1999 and June-August 2000. Each team included a team leader and three team members. Team

Table 2 Number of sites, health facilities, distribution points, health providers, and mothers included in survey

\begin{tabular}{lccc} 
& Togo & Burkina Faso & Total \\
\hline Cities & 6 & 10 & 16 \\
\hline Health facilities $^{*}$ & 11 & 32 & 43 \\
\hline Distribution points $\dagger$ & 20 & 46 & 66 \\
\hline Health providers $\ddagger$ & 95 & 91 & 186 \\
\hline Mothers & 52 & 53 & 105
\end{tabular}

*Hospitals, maternity units, mother and child clinics, community health centres.

†Pharmacies, shops, supermarkets.

‡ Physicians, nurses, midwives. leaders ensured quality of the data collection process. All team members participated in a three day training workshop to standardise data collection. Survey teams stayed in each site until data collection was completed (1-4 days per survey site). At the end of each day a meeting allowed survey team leaders to monitor the quality of the data collection process and plan the next day's data collection strategy. Team leaders contacted the survey coordinator every day. Data were entered, tabulated, and analysed with EpiInfo v6.04c.

\section{Results}

Tables 1 and 2 show the number of sites, health facilities, distribution points, health providers, and mothers included in the survey.

Donations to health facilities and health providers In Togo, 11 health facilities were included in the survey, nine were public and two were private. In Burkina Faso, 32 health facilities were included in the survey, 24 were public and eight were private. Two of the health facilities in Togo and 20 of those in Burkina Faso were officially certified as Baby Friendly.

Table 3 Nature of health facilities that received donations of products within scope of international code in six months before survey

\begin{tabular}{lll} 
Country & Type & Baby Friendly* \\
\hline Togo & Public & No \\
\hline Burkina Faso & Public & Yes \\
\hline Burkina Faso & Public & Yes \\
\hline Burkina Faso & Public & No \\
\hline Burkina Faso & Public & No \\
\hline Burkina Faso & Private & No
\end{tabular}

*Officially certified as compliant with criteria for successful breast feeding according to Baby Friendly Hospital Initiative.

In Togo, one public health facility had received donations of infant formula in the six months before the survey. This health facility was not certified as Baby Friendly (table 3). By the time of the survey, all such donations had been given free of charge to mothers and the facility was not receiving any more donations. In Burkina Faso, five health facilities had received donations of breast milk substitutes in the six months before the survey. Four of these facilities were public and one private. Two of the public facilities were certified as Baby Friendly and two were not. The private facility was not certified as Baby Friendly (table 3). Five facilities had received infant formula, one had received complementary foods, one had received biscuits, and one had received feeding bottles. At the time of the survey, three of the five facilities were receiving donations of breast milk substitutes and were giving them to mothers free of charge. These products were Beba-Nestlé (two health facilities) and Nativa (one health facility), both manufactured by Nestlé.

Health providers in one health facility in Togo and four health facilities in Burkina Faso had received free samples of commercial breast milk substitutes in the six months before the survey. None of the recipients was involved with research or professional evaluation activities. Donations to health providers included SMA (infant formula; Wyeth) in three health facilities, AL-110 and Preguigoz (infant formula; Nestlé) in one 
health facility, and Cerelac (milk cereal complementary food; Nestlé) in one health facility. In Burkina Faso, health providers in five health facilities had received promotional gifts from manufacturers. Gifts were donated for personal and professional use and included pens, highlighters, measuring tapes, obstetric stethoscopes, and notepads. These gifts carried the brand name "Nestlé" (three cases) or "Danone Baby Foods" (two cases).

\section{Informational or educational materials in healthcare systems}

"Informational" and "educational" materials produced by manufacturers of breast milk substitutes were found in one health facility in Togo and six health facilities in Burkina Faso.

In Togo, one health facility displayed a large calendar with pictures of mothers and their infants, a teddy bear, and the legend "Danone Baby Food." In Burkina Faso we found a leaflet on Nestlé Nativa 1 for health providers in one health facility. This leaflet contained non-factual information and did not provide information on the superiority of breast feeding but focused on "how to cover the nutritional requirements of infants whose mothers cannot breast feed or stop breast feeding early, or when breast milk is insufficient." It conveyed the idea that it is normal for women not to breast feed and that there is an alternative comparable with human milk ("the qualitative composition of Nativa 1 is based on that of breast milk"). Similar leaflets on Nestlé Guigoz 1 and Nestlé Guigoz 2 were found in a health facility in Burkina Faso.

The publication Les avantages de Cérélac (the advantages of Cérélac) by Nestlé was found in a health facility in Burkina Faso. This leaflet, labelled as "exclusively reserved for the medical profession" contained no information on the composition of the product but contained information for caregivers on how to prepare the infant food at home (Comment préparer Cérélac?). The leaflet Cérélac: 5 Différentes Variétés pour le Bien-être du Bébé (Cérélac: five different varieties for the wellbeing of the child) by Nestlé was found in a health facility in Burkina Faso. This publication for mothers of young infants included two pictures of babies, advertised various products manufactured by Nestlé, and made no reference to the superiority of breast feeding.

None of the promotional materials mentioned above included factual information on the negative effects on breast feeding of introducing breast milk substitutes or the difficulty of reversing the decision not to breast feed. Several copies of the Carnet de santé de la mère et de l'enfant (Health card of the mother and the infant) by Nestlé were found in a health facility in Burkina Faso. This publication for mothers advertised breast milk substitutes and did not provide any information on the superiority of breast feeding and the health hazards of breast milk substitutes.

\section{Health providers' knowledge of code}

We interviewed 186 health providers (95 in Togo and 91 in Burkina Faso) to gather information on their knowledge about the code.

In Togo, 81 health providers had never heard about the code. Only nine of the 14 who had heard about the code had read any or all of it. None of the 95 interviewed had participated in any training on the code. Fifty eight had heard about the Baby Friendly Hospital Initiative, and 12 had received some formal training on it but only four worked in a Baby Friendly facility.

In Burkina Faso, 67 health providers had never heard about the code. Only 15 of the 24 who had heard about the code had read any or all of it, and only four had received some training. Thirty eight had heard about the Baby Friendly Hospital Initiative. Only 15 of them had participated in training on the initiative, but 36 worked in a Baby Friendly facility.

Counselling and marketing aimed at mothers

We interviewed 105 mothers of infants aged $\leqslant 5$ months (52 in Togo and 53 in Burkina Faso) to gather information on their main sources of information and counselling on breast feeding.

In Togo, nine mothers identified a friend or relative as the main source of advice on infant feeding; 27 identified a health provider as the main source of advice; and 16 said that nobody gave them advice on how to feed their infants. Twenty four mothers said that their health providers had never given them any advice on breast feeding.

In Burkina Faso, one mother said that she decided how to feed her baby based on media information; nine identified a relative as the main source of advice; nine identified a health provider as the main source of advice; and 38 said that nobody gave them advice on how to feed their infants. Forty two mothers said that their health providers had never given them any advice on breast feeding. None of the mothers had been approached by representatives of manufacturers of breast milk substitutes either in Togo or in Burkina Faso.

Labelling and promotion of breast milk substitutes in distribution points

We surveyed 20 distribution points (14 pharmacies and six shops or supermarkets) in Togo and 46 distribution points (23 pharmacies and 23 shops or supermarkets) in Burkina Faso. We checked labelling of all breast milk substitutes against the standards set forth by article 9 of the code. We found 40 products within the scope of the code (one sold only in Togo, five sold only in Burkina Faso, and 34 sold in both countries) that violated one or more of the provisions of the code (table 4). These products were infant formula, milk-cereal complementary foods, complementary foods based on vegetables or fruit, fruit juice, bottles, and pacifiers. Most breast milk substitutes that did not comply with the labelling standards of the code were produced by international manufacturers, with Danone and Nestlé having an overwhelming presence. Over half (21) of the breast milk substitutes that violated labelling standards were manufactured by Danone; 11 were manufactured by Nestlé and eight by other national or international manufacturers. Table 4 gives details of labelling violations by manufacturer and type of breast milk substitute. We found special displays advertising specific brands of breast milk substitutes in six distribution points in Togo and 23 distribution points in Burkina Faso. One pharmacy in Togo distributed free samples of breast milk substitutes to mothers.

\section{Advertisement to general public in news media}

We found only one advertisement for breast milk substitutes in national newspapers: Sodepal advertised a 
Table 4 Violations of international code in Togo and Burkina Faso on labelling of breast milk substitutes

\begin{tabular}{|c|c|c|c|c|c|c|c|c|c|c|c|}
\hline & $\begin{array}{c}\text { No of } \\
\text { products } \\
\text { violating } \\
\text { code }\end{array}$ & $\begin{array}{l}\text { Recommends } \\
\text { inappropriate } \\
\text { age of } \\
\text { introduction }\end{array}$ & $\begin{array}{c}\text { No } \\
\text { statement on } \\
\text { superiority } \\
\text { of breast } \\
\text { feeding } \\
\end{array}$ & $\begin{array}{l}\text { Does not say } \\
\text { use only on } \\
\text { advice of } \\
\text { health provider }\end{array}$ & $\begin{array}{c}\text { No } \\
\text { instructions } \\
\text { for } \\
\text { appropriate } \\
\text { preparation }\end{array}$ & $\begin{array}{l}\text { No warning } \\
\text { against health } \\
\text { hazards of } \\
\text { inappropriate } \\
\text { use }\end{array}$ & $\begin{array}{c}\text { Pictures, } \\
\text { drawings, or } \\
\text { text } \\
\text { idealising } \\
\text { use }\end{array}$ & $\begin{array}{c}\text { No } \\
\text { information } \\
\text { on storage }\end{array}$ & $\begin{array}{c}\text { Suggests/ } \\
\text { recommends } \\
\text { use of } \\
\text { feeding } \\
\text { bottle }\end{array}$ & $\begin{array}{c}\text { No } \\
\text { information } \\
\text { on } \\
\text { composition/ } \\
\text { analysis }\end{array}$ & $\begin{array}{c}\text { Inappropriate } \\
\text { Ianguage } \\
\left({ }^{\star}\right)\end{array}$ \\
\hline \multicolumn{12}{|l|}{ Infant formula: } \\
\hline Nestlé & 3 & 3 & & & & 2 & & & 1 & & 1 \\
\hline Danone & 3 & 3 & 1 & 1 & & 1 & & & & & \\
\hline Wyeth & 1 & 1 & & & & 1 & & & & & \\
\hline \multicolumn{12}{|c|}{ Milk-cereal complementary food: } \\
\hline Danone & 8 & 8 & & 1 & & 8 & 3 & 1 & 2 & & \\
\hline Nestlé & 1 & 1 & & & & 1 & & & & & \\
\hline Protein-Kisser & 1 & 1 & & 1 & & 1 & 1 & & & & \\
\hline Unite Den Mugu & 1 & 1 & & & & 1 & 1 & 1 & & & \\
\hline Sodepal & 1 & 1 & & 1 & 1 & 1 & & 1 & & 1 & \\
\hline $\begin{array}{l}\text { Centre Feminin } \\
\text { d'Aliments de } \\
\text { Sevrage }\end{array}$ & 1 & 1 & & & & 1 & 1 & & & & \\
\hline $\begin{array}{l}\text { Societe Eaoun et } \\
\text { Fils }\end{array}$ & 1 & 1 & & & 1 & 1 & & & 1 & & \\
\hline AJOC & 1 & 1 & & & & 1 & 1 & 1 & & & \\
\hline \multicolumn{12}{|c|}{ Vegetable or fruit based complementary food: } \\
\hline Danone & 6 & 6 & & & & 6 & & & & & \\
\hline Nestlé & 1 & 1 & & & & 1 & & & & & \\
\hline \multicolumn{12}{|l|}{ Fruit juice: } \\
\hline Danone & 4 & 4 & & & & 1 & & & & & \\
\hline Nestlé & 3 & 3 & & & & 3 & & & & & \\
\hline \multicolumn{12}{|l|}{ Bottles/pacifiers: } \\
\hline Camera & 1 & & & & & 1 & 1 & & & & 1 \\
\hline Remond & 1 & & & & & 1 & & & & & \\
\hline Dodie & 1 & & & & & & 1 & & & & \\
\hline Total & 40 & 37 & 2 & 4 & 2 & 39 & 9 & 4 & 5 & 1 & 2 \\
\hline
\end{tabular}

*Language other than French. No label in any of local languages was found.

milk-cereal complementary food (Vitaline) in the daily national newspaper, l'Observateur Paalga, in Burkina Faso. The advertisement included the picture of a baby with the legend "Bébé en forme" (healthy baby) and recommended that babies were fed this complementary food from the age of 4 months. Advertisement of breast milk substitutes in the international newspapers was common. All international journals advertising breast milk substitutes were published in France. The French magazine Parents (distributed in Burkina Faso) included promotional information on breast milk substitutes manufactured by Danone, Nestlé, and Chicco. Similarly, the French magazine Enfant (distributed in Togo and Burkina Faso) included promotional information, images, or text idealising the use of breast milk substitutes produced by Danone and Nestlé. There was no broadcasting of promotional information of breast milk substitutes through national television or radio networks. There were no advertisements for breast milk substitutes on city billboards or any other public space in Togo. In Burkina Faso, Protein-Kisser advertised breast milk substitutes on city billboards in the main streets of Ouagadougou.

\section{Discussion}

The code inside the healthcare system

Our study shows that manufacturers of breast milk substitutes are using national healthcare systems in Togo and Burkina Faso to promote their products and to distribute free samples to mothers (violation of article 6.7). The negative effect on breast feeding of giving free samples of breast milk substitutes to mothers is well documented. ${ }^{4}$ Health systems are also being used to distribute free samples to health providers for purposes other than professional research or evaluation (violation of article 7.4) and to distribute material inducement to promote products within the scope of the code (violation of article 7.3). The presence of such promotional gifts in the professional environment, observed in audits endorsed by breast milk manufacturers themselves, ${ }^{5}$ conveys a message of health providers' endorsement of breast milk substitutes. ${ }^{6}$ The presence of promotional materials for pregnant women and mothers that idealise the use of breast milk substitutes (pictures of healthy babies) and without clear information on the superiority of breast feeding, the negative effects on breast feeding of introducing breast milk substitutes, or the difficulty of reversing the decision not to breast feed (violations of articles 4.2 and 4.3) further show that manufacturers are using national healthcare systems to market their products.

\section{The code outside the healthcare system}

Violations of the code are not limited to the healthcare system. Of particular concern are violations related to the labelling of breast milk substitutes. Labels must provide the necessary information about the appropriate use of the product so as not to discourage breast feeding (article 9.1); neither the container nor the label must include pictures or text that may idealise the use of infant formula (article 9.2); labels must provide clear, easily readable, and understandable information in an appropriate language and include a statement on the superiority of breast feeding, a statement that the product should be used only on the advice of a health 
provider, instructions for appropriate preparation, a warning of the health hazards of inappropriate preparation, information on composition of the product, and information on the storage conditions required (articles 9.2 and 9.4). Our survey identified 40 commercial breast milk substitutes that violated one or more of these labelling standards. Twenty one of these breast milk substitutes were manufactured by Danone, 11 by Nestlé, and eight by other national or international manufacturers.

\section{Responsibilities of government, health professionals, and manufacturers}

The International Association of Infant Food Manufacturers is committed to support the principles of the code in its entirety. ${ }^{7}$ However, code violations by manufacturers continue to be reported in industrialised and developing countries. ${ }^{8-10}$ A recent multicentre study showed that leading manufacturers were violating the code in Thailand, Bangladesh, South Africa, and Poland. ${ }^{11}$ Workers inside the companies have also reported evidence of manufacturers' malpractice in developing countries. ${ }^{12}$ Using standardised survey methods, our study provides conclusive evidence that breast milk manufacturers are also violating the code in Togo and Burkina Faso.

This situation requires urgent policy action to ensure that families are provided with objective and consistent information on child feeding (article 4.1) at a time when appropriate counselling can make the difference between life and death. Data show that infant mortality in Togo and Burkina Faso is among the highest in the world ${ }^{13}$ and that a considerable proportion of those infant deaths are attributable to suboptimal breast feeding. Every year suboptimal breast feeding is the underlying cause of an estimated 3300 infant deaths in Togo $^{14}$ (25\% of all cause infant mortality) and over 6200 infant deaths in Burkina Faso ${ }^{15}$ (11\% of all cause infant mortality).

The development of national legislation to regulate the marketing of breast milk substitutes is a key component of a comprehensive strategy to protect, promote, and support breast feeding. However, our study shows comparable levels of violations with (Burkina Faso) or without (Togo) such legislation.

Governments have an obligation to ensure that legislation is accompanied by effective training, information, and monitoring systems so that scientific knowledge rather than marketing practices guides health professionals' practices. ${ }^{16}$ Health professionals' endorsement (implicit or explicit) of commercial breast milk substitutes can have a strong impact on caregivers' decisions about breast feeding at a time when it is optimal for the infant. Health professionals must support the code. In the context of the HIV pandemic it becomes increasingly urgent to ensure the proper use of breast milk substitutes among HIV positive women who, fully informed, chose to use them. It is also crucial to reduce the amount of replacement feeding among women without HIV infection and women who do not know (or chose not to know) their HIV status. ${ }^{17}$ In the face of HIV and AIDS, support for breast feeding must be strengthened. ${ }^{18}$

The burden of compliance with the code, however, rests with manufacturers themselves. ${ }^{19}$ Manufacturers have an obligation to comply with the standards in the

\section{What is already known on this topic}

All member states of the World Health Assembly have reaffirmed their support for the International Code of Marketing of Breastmilk Substitutes

Violations by manufacturers of breast milk substitutes have been reported in industrialised and developing countries

\section{What this study adds}

Manufacturers of breast milk substitutes are violating the code in Togo and Burkina Faso

The levels of code violations are similar in a country with (Burkina Faso) and one without (Togo) legislation on the marketing of breast milk substitutes

Legislation must be accompanied by effective information, training, and monitoring systems to ensure compliance with the code

code. They should not use healthcare systems to provide mothers with free samples of their products, to disseminate promotional materials containing incomplete and biased information, and to promote the use of breast milk substitutes among health professionals and mothers of young infants. Manufacturers must not use distribution points to promote their products. They must stop using the news media to idealise the use of breast milk substitutes. Lastly, they must label their products according to the directives of the code.

The evidence from this large systematic survey of health facilities, distribution points, health providers, and mothers in Togo and Burkina Faso shows that in west Africa manufacturers of breast milk substitutes do not have in place "a consistent framework of policies, procedures, and work instructions to ensure compliance with the code" and that the code is far from being "part of the corporate culture" as manufacturers of breast milk substitutes claim. ${ }^{17} 20$

We thank Andrée Bassouka, head of the nutrition division at the Ministry of Health in Togo, and Léon Sanon, head of the National Centre for Nutrition in Burkina Faso.

Contributors: VMA had the original idea for the study, designed and coordinated the study, conducted the final analysis, interpreted the data, and prepared the manuscript; he will act as guarantor. JSR and ANO assisted with design, interpretation, and presentation. SK coordinated data collection and assisted with the preliminary analysis. Aoua Zerbo (team leader), Madeleine Da, Franceline Ilboudou, and Blanche Bationo collected the data in Burkina Faso. Faustin Amoussou (team leader), Angele Gbare, Eliane Guey, and Irene Amenyah collected the data in Togo. Luann Martin (LINKAGES) edited and reviewed the manuscript.

Funding: This paper is a product of the LINKAGES (Breastfeeding, LAM, Complementary Feeding, and Maternal Nutrition) project. LINKAGES is supported by G/PHN/HN, the US Agency for International Development (USAID) under the terms of Grant No HRN-A-00-97-00007-00. LINKAGES project is managed by the Academy for Educational Development (AED). The opinions expressed in this paper are those of the authors and do not necessarily reflect the views of USAID.

Competing interests: None declared.

1 World Health Organization. International code of marketing of breastmilk substitutes. Geneva: World Health Organization, 1981. 
2 Haggerty PA, Rutstein SO. Breastfeeding and complementary infant feeding, and the postpartum effects of breastfeeding. Calverton, MA: Macro International, 1999 (DHS comparative studies No 30).

3 Mehdi T, Wagner-Rizvi T. Feeding fiasco: pushing commercial infant foods in Pakistan. Islamabad, Pakistan: The Network: Association for rational use of medication in Pakistan, 1998.

4 Frank DA, Wirtz JS, Sorenson JR, Heeren T. Commercial discharge packs and breastfeeding counseling: effects on infant feeding practices in a randomized trial. Pediatrics 1987;80:845-54.

5 Yamey G. Nestlé violates international marketing code, says audit. BMJ 2000;321:8.

6 Jellife DB. Commerciogenic malnutrition. Nutr Rev 1972;30:199-205.

7 Sokol E, Allain A. Complying with the code? A manufacturer's and distributor's guide to the code. Penang, Malaysia: International Baby Food Action guide to the code.
Network, 1998 .

8 Pisacane A. Nestlés violation of international marketing code. Similar practices take place in Europe. BMJ 2000;321:960

9 Costello A, Sachdev HS. Protecting breast feeding from breast milk substitutes. BMJ 1998;316:1103-4.

10 Sokol E, Thiagarajah S, Allain A. Breaking the rules. Stretching the rules. Evidence of violations of the code of marketing of breastmilk substitutes and subsequent resolutions. Penang, Malaysia: International Baby Food Action Network, 2001.
11 Taylor A. Violations of the code of marketing of breast milk substitutes: prevalence in four countries. BMJ 1998;316:1117-22.

12 Yamey G. Nestlé accused of breaking international code. BMJ 2000;320:468.

13 Unicef. The state of the world's children. New York: Unicef, 2002

14 LINKAGES. Nutrition au Togo. Investissons aujourd'hui pour un développement durable. [Nutrition in Togo. Investing today for sustainable development.] Washington, DC: Academy for Educational Development, 1999.

15 LINKAGES. La nutrition: clé du développement humain durable au Burkina Faso. [Nutrition: key to sustainable development for Burkina Faso.] Washington, DC: Academy for Educational Development, 2000.

16 Perera T. National code of marketing of formula milks is not properly implemented in Sri Lanka. BMJ 1999;318:1140.

17 Lhotska L, Armstrong H. Future directions. Ann NY Acad Sci 2000;918:145-55.

18 Bellamy C. Unicef and baby food manufacturers. BMJ 2000;321:960.

19 Kean YJ. Nestlé's violation of international marketing code. Audit's report fudges the issue. BMJ 2000;321:959-60.

20 Sinha S. Nestlés violation of international marketing code. The auditors respond. BMJ 2000;321:959

(Accepted 12 September) 